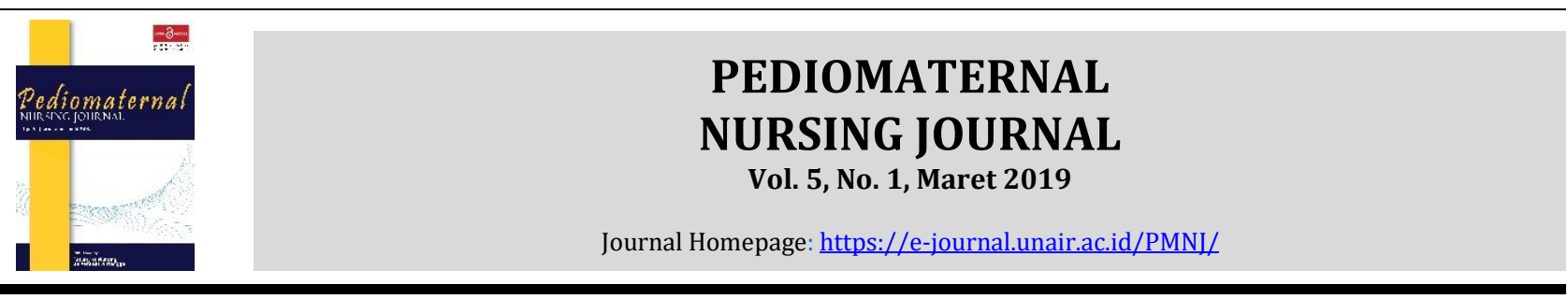

Original Research

\title{
Hubungan Data Demografi Keluarga dalam Pemberian ASI Esklusif Anak Balita Stunting
}

\section{(Relationship between Family Demographic Data in Providing Exclusive Breastfeeding of Children with Stunting)}

\author{
Putri Dewi Suciningtyas, Mira Triharini, dan Praba Diyan Rachmawati \\ Fakultas Keperawatan, Universitas Airlangga, Surabaya, Jawa Timur, Indonesia
}

ARTICLE HISTORY
Received: May 7, 2019
Accepted: May 27, 2019
KEYWORDS
mother age; education;
employment; stunting
CORRESPONDING AUTHOR
Putri Dewi Suciningtyas
putri.dewi.suciningtyas-
2017@fkp.unair.ac.id
Fakultas Keperawatan,
Universitas Airlangga, Surabaya,
Jawa Timur, Indonesia

Cite this as:

\begin{abstract}
Introduction: Stunting is an important nutritional problem in Indonesia because it has a serious impact on the quality of child development. Stunting is thought to be related to family demographics, and environmental conditions. The purpose of this study is to explain the relationship between family demographic factors including age, occupation, income and number of families with stunting nutritional status.

Methods: This Study was Cross-Sectional Study. The population in this study were mothers with stunting toddlers aged 2-5 years at the Puskemas Galis Bangkalan with a total sample of 129 respondents, taken according to the inclusion criteria. The independent variables are age of respondents, education, employment, family members and the dependent variable is stunting nutritional status. Data was collected using a structured questionnaire and observation of respondents. The data were then analyzed using the Rank Spearman test with a significance level of $<0.05$.

Results: The results showed that there was no relationship between age of respondents $(p=0.305)$, education $(p=0.712)$, employment $(p=0.261)$, family members $(p=0.153)$ with stunting of nutritional status.

Conclusion: Factors that affect the health of toddler with the nutritional status of stunting toddlers are very multifactorial so that support is needed across sectors to reduce the stunting of nutritional status.
\end{abstract}

Suciningtyas, P. D., Triharini, M., \& Rachmawati, P. D. (2019). Hubungan Data Demografi Keluarga dalam Pemberian ASI Esklusif Anak Balita Stunting. Pediomaternal Nurs. J., 5(1), 131-136.

\section{PENDAHULUAN}

Permasalahan gizi dialami oleh banyak negara. Masalah Gizi yang terjadi salah satunya pada masa balita. Masa balita merupakan kelompok umur yang rawan gizi dan penyakit (1). Status gizi merupakan indikator kesehatan yang penting bagi balita. Di Indonesia salah satu permasalahan gizi yang belum terselesaikan adalah stunting (2). Stunting menunjukan ketidakcukupan gizi dalam jangka waktu lama (kronis), yang dimulai sebelum kehamilan, saat kehamilan, dan kehidupan setelah dilahirkan. Stunting memiliki efek jangka panjang, diantaranya dapat mempengaruhi perkembangan kognitif anak, mempengaruhi produktivitas ekonomi saat dewasa, dan juga mempengaruhi maternal reproductive outcomes (3).

Fungsi keluarga merupakan salah satu faktor yang mempengaruhi status kesehatan anak. Keluarga dalam melakukan perawatan terhadap anak harus saling, mendukung, menghargai, serta meningkatkan kekuatan dan kompetensi dalam memberikan asuhan kepada anak (4). Ibu berperan dalam memberikan nutrisi pada anak, otonomi seorang ibu berdampak pada perawatan anak dan kecukupan nutrisi, ibu yang mempunyai otonomi yang tinggi mampu mengambil 
keputusan mengenai kesehatan keluarga (5). Kehadiran orangtua dalam perawatan dan pemberian asupan nutrisi pada anak sangat sangat penting .

Asia selatan dan Afrika sub-Sahara merupakan wilayah yang angka kejadianya tinggi dari tempat lain (6). Prevalensi stunting di Indonesia lebih tinggi daripada negara-negara lain di Asia Tenggara, seperti Myanmar (35\%), Vietnam (23\%), dan Thailand (16\%). Berdasarkan Global Nutrition Report tahun 2014, Indonesia merupakan negara dengan urutan ke-17 dari 117 negara yang memiliki masalah gizi kompleks masalah gizi kurang (19.6\%) dan stunting (37.2\%). Menurut (7) prevalensi stunting menjadi masalah kesehatan masyarakat jika prevalensinya $20 \%$ atau lebih, secara global sekitar 162 juta anak balita terkena stunting. Indonesia termasuk dalam 14 negara dengan angka balita stunting terbesar dan menempati urutan ke 5 setelah India, Nigeria, Pakistan dan Cina (8). Data Pemantauan Status Gizi nasional terakhir tahun 2017 menyebutkan daerah di Jawa Timur dengan stunting atau prevalensi $18.8 \%$. Sebelas Kabupaten terindikasi terjadi permasalahan stunting, salah satu wilayah yang terkena stunting adalah di wilayah Bangkalan yaitu sebesar32\% (Lestari,et al, 2015). Berdasarkan hasil sudi pendahuluan Dinas Kesehatan KabupatenBangkalan tercatat balita $5.73 \%$ atau sekitar 307 balita yang terkena stunting salah satu wilayahnya terbanyak di Puskesmas Galis sekitar 129 balita yeng terkena stunting sangat pendek.

Penelitian mengenai faktor kejadian stunting pada balita 12-24 bulan sudah banyak dilakukan. Faktor faktornya antara lain tinggi badan ayah riwayat berat badan lahir rendah, riwayat gizi kurang, kurangnya pemanfaatan posyandu perilaku hiegene ketidakikutsertaan dalam pemberian makanan pendamping atau MPASI (9). Pemberian Imunisasi, pendapatan rumah tangga, pendidikan ibu,riwayat ASI Eklusif, pengetahuan gizi juga termasuk dalam faktor balita terjadi stunting (10). Status data demografi keluarga seperti pendidikan orang tua, pendapatan keluarga, dan jumlah keluarga secara tidak langsung dapat berhubungan dengan kejadian stunting (12). Status ekonomi keluarga yang rendah akan mampu berdampak sangat signifikan terhadap status gizi stunting (13). Karakteristik keluarga merupakan faktor yang mempengaruhi terhadap pola konsumsi dalam pemenuhan gizi pada anak balita. Karakteristik keluarga umur ibu, pendidikan, pekerjaan, dan jumlah keluarga merupakan aspek yang berpengaruh terhadap usaha peningkatan gizi masyarakat, yang mencakup tingkat konsumsi keluarga. Hal tersebut menentukan besar kecilnya penggunaan pendapatan keluarga dalam melaksanakan kebutuhan makananan sehari-hari untuk dikonsumsi oleh seluruh keluarga (14).

Dalam mendukung keberhasilan pencapaian sasaran pembangunan kesehatan sesuai Rencana Strategis tahun 2015-2019, Kementerian Kesehatan telah menetapkan kebijakan operasional anatara lain pembangunan kesehatan periode 2015-2019 akan difokuskan pada empat area prioritas salah satunya adalah perbaikan Gizi Masyarakat khususnya untuk pengendalian prevalensi Balita Pendek (stunting). Pemerintah pusat dan pemerintahan daerah menetapkan kebijakan pembangunan keluarga melalui pembinaan ketahanan dan kesejahteraan keluarga, untuk mendukung keluarga agar dapat melaksanakan fungsinya secara optimal. Keluarga sebagai fokus dalam pendekatan pelaksanaan progam Indonesia sehat (8). Tujuan penelitian ini untuk mengetahui hubungan antara data demografi terdiri atas umur ibu, pendidikan, pekerjaan, jumlah keluarga terhadap status gizi stunting pada balita.

\section{METODE}

\subsection{Desain}

Penelitian yang dilakukan merupakan jenis penelitian deskriptif cross sectional.

\subsection{Populasi, sampel, dan sampling}

Populasi dalam penelitian ini adalah semua ibu balita di wilayah puskesmas Galis sebanyak 186 ibu dengan status balita stunting didapatkan $129 \mathrm{ibu}$ dengan balita stunting dengan purposive sampling. Penelitian dilaksanakan 24 Oktober-31 December 2018. Inklusi kriteria adalah Ibu responden yang tinggal dalam satu rumah dan merawat langsung, Keluarga yang tinggal dalam satu rumah (ayah), Balita usia 2-5 tahun dengan status gizi stunting Kriteria eksklusi adalah Balita usia 2-5 Tahun yang menderita penyakit kronis misalnya jantung bawaan Pada saat dilakukan penelitian sedang tidak berada diwilayah tersebut untuk jangka waktu lama dan Balita dengan kebutuhan Khusus misalnya Autis, ADHD

\subsection{Variabel}

Variabel independen dalam penelitian ini adalah umur ibu, pendidikan, pekerjaan, dan jumlah keluarga. Variabel dependen adalah status gizi balita stunting

\subsection{Instrumen}

Kuesioner umur responden terdiri dari pilihan $<18$ tahun, 18-35 tahun, 36-50 tahun, >50 tahun. Kuesioner Pendidikan terakhir terdiri dari tidak tamat sekolah, SD, SMP, SLTA, Perguruan Tinggi. Kuesioner Pekerjaan Responden terdiri dari Tidak bekerja, Buruh, Pelajar, Wiraswasta, Pegawai negeri, lain-lain serta jumlah keluarga dan observasi status gizi stunting dengan pengukuran tinggi badan balita $(\mathrm{TB} / \mathrm{U})$ dikatakan sangat pendek jika $<3,0 \mathrm{SD}$, dan dikatakan pendek antara -3.0 SD- <-2.0 SD.

\subsection{Prosedur}

Peneliti berkoordinasi dengan semua bidan desa dan semua anggota kader yang berada di wilayah kerja puskesmas Galis untuk menyampaikan informasi kepada ibu balita yang stunting usia 2 sampai 5 tahun untuk berkumpul di posyandu desa masing masing sesuai jadwal posyandu. Pembagian kuesioner kepada responden tidak dilakukan secara bersamaan tetapi sesuai dengan setiap ibu balita yang datang 
saat itu peneliti memperkenalkan diri dahulu, menjelaskan tujuan dan prosedur pengambilan data penelitian, serta meminta persetujuan kepada responden. Setiap balita yang memenuhi kriteria inklusi diberikan Informed Consent untuk ditandatangani dan selanjutnya diberikan lembar kuesioner untuk diisi, dilakukan pengukuran tinggi badan. Memberikan kuesioner tentang data demografi responden. Setelah semua responden mengisi kuesioner dikumpulkan menjadi satu kemudian peneliti mengambil dan mengecek ulang apakah kuesioner sudah terisi semua atau belum. Setelah semua sampel yang ditetapkan terpenuhi, kemudian peneliti melakukan pengolahan data untuk dianalisis dengan menggunakan bantuan SPSS. tahundengan persentase sebanyak 102 orang (79.1\%). Pendidikan Terakhir terbanyak yaitu SD 77 responden (59.7\%). Mayoritas responden tidak bekerja sebanyak 62 responden (48.1\%). Jumlah Keluarga mayoritas 4-6 anggota keluarga sebanyak 70 responponden (54.3\%). Status gizi stunting pada balita menunjukan terdapat 36 balita (27.9\%) severely stunted, terdapat 93 balita (72.1\%) dengan balita stunted. Umur responden dengan status gizi balita stunting menunjukan hasil analisi statsitik menggunakan uji sperman rho dengan tingkat kemaknaan $<0,05$ didapat dengan nilai $(p=0,305)$ yang menunjukan tidak ada hubungan antara umur responden dengan status gizi balita stunting. Pendidkan terakhir responden dengan status gizi

Tabel 1. Distribusi Karakteristik Responden ( $n=273)$

\begin{tabular}{|c|c|c|c|c|c|}
\hline \multirow{3}{*}{ Karakteristik } & \multicolumn{4}{|c|}{ Status Gizi Stunting } & \multirow{3}{*}{$\mathbf{p}$} \\
\hline & \multicolumn{2}{|c|}{ Pendek } & \multicolumn{2}{|c|}{ Sangat Pendek } & \\
\hline & $\mathbf{n}$ & $\%$ & $\mathbf{n}$ & $\%$ & \\
\hline \multicolumn{6}{|l|}{ Umur Responden } \\
\hline$<18$ Tahun & 1 & 0,8 & 0 & 0 & \\
\hline 18-35 Tahun & 73 & 56,6 & 29 & 22,5 & 0,305 \\
\hline 36-50 Tahun & 17 & 13,2 & 7 & 5,4 & \\
\hline$>50$ Tahun & 2 & 1,6 & 0 & 0 & \\
\hline \multicolumn{6}{|l|}{ Pendidikan Terakhir } \\
\hline Tidak Tamat SD & 11 & 8,5 & 4 & 3,1 & \\
\hline SD & 55 & 42,6 & 22 & 17,1 & \\
\hline SMP & 18 & 14,0 & 4 & 3,1 & 0,712 \\
\hline SMA & 9 & 7,0 & 5 & 3,9 & \\
\hline Perguruan Tinggi & 0 & 0 & 1 & 0,8 & \\
\hline \multicolumn{6}{|l|}{ Pekerjaan } \\
\hline Tidak Bekerja & 48 & 37,2 & 15 & 11,6 & \\
\hline Buruh/Tani & 27 & 20,9 & 12 & 9,3 & 0,261 \\
\hline Wiraswasta & 18 & 14,0 & 7 & 5,4 & \\
\hline Lainya & 0 & 0 & 2 & 1,6 & \\
\hline \multicolumn{6}{|l|}{ Jumlah Keluarga } \\
\hline $1-3$ & 9 & 7,0 & 3 & 2,3 & \\
\hline $4-6$ & 46 & 35,7 & 24 & 18,6 & 0,153 \\
\hline $7-10$ & 34 & 26,4 & 9 & 7,0 & \\
\hline$>10$ & 4 & 3,1 & 0 & 0 & \\
\hline
\end{tabular}

\subsection{Analisis}

Penelitian ini dilakukan analisis dengan IBM SPSS Statistic 22. Dari data yang terkumpul sebelumnya telah diuji normalitas oleh peneliti, dari hasil uji normalitas didapatkan tidak berdistribusi normal. Peneliti mneganailis data demografi dengan menggunakan uji Spearmean's Rho with significant $\alpha \leq 0.05$.

\subsection{Ethical Clearance}

Penelitian ini telah dinyatakan lolos kaji etik dan mendapatkan sertifikat Ethical Approval dengan No. 1197-KEPK yang dikeluarkan oleh Komite Etik Penelitian Kesehatan Fakultas Keperawatan Universitas Airlangga pada tanggal 3 Desember 2018.

\section{Hasil}

Karakteristik responden menunjukan dari segi umur, semua responden berada pada usia 18-35 balita stunting didapat dengan nilai $(p=0,712)$ yang menunjukan tidak ada hubungan antara Pendidikan terakhir responden dengan status gizi balita stunting.Pekerjaan responden dengan status gizi balita stunting didapat dengan nilai $(p=0,261)$ yang menunjukan tidak ada hubungan antara Pekerjaan responden dengan status gizi balita stunting. Jumlah keluarga dengan status gizi balita stunting didapatkan nilai $(\mathrm{p}=0,153)$ yang menunjukan tidak ada hubungan antara Jumlah keluarga responden dengan status gizi balita stunting [Tabel 1].

\section{PEMBAHASAN}

Mayoritas ibu dalam penelitian ini memiliki umur 1835 tahun, , jumlah keluarga terbanyak 4-6 anggota keluarga. Hasil penelitian ini tidak ada hubungan yang signifikan antara status gizi balita stunting. Menurut deskriptif umur ibu 18-35 tahun menunjukan bahwa pada usia tersebut menunjukan dalam usia yang matang dan dewasa. Usia antara 21 - 
35 tahun orang akan mencapai puncak kekuatan motorik dan merupakan masa penyesuaian diri terhadap kehidupan dan harapan sosial baru yang berperan sebagai orangtua (15). Penelitian ini tidak sejalan dengan pendapat Soetjiningsih yang menyatakan bahwa faktor keluarga dan adat istiadat setempat dapat mempengaruhi tumbuh kembang anak antara lain pekerjaan atau pendapatan, pendidikan ibu atau ayah, dan jumlah saudara (16). Bertambahnya umur seseorang maka akan terjadi perubahan aspek mental dan psikologis sehingga pemikiran menjadi dewasa, umur yang matang diharapkan mampu memberikan asupan nutrisi anak yang baik dan usia ibu 36-50 tahun memiliki pengalaman yang banyak dalam memberikan pengasuhan pada anaknya.

Mayoritas pendidikan ibu adalah SD dimana jumlah balita yang mengalami stunting terbayak diantara para ibu yang berpendidikan SMP,SMA, dan perguruan tinggi, penelitian ini tidak ada hubungan yang signifikan antara pendidikan dengan status gizi balita stunting. Pendidikan orangtua merupakan salah satu faktor yang penting dalam tumbuh kembang anak. Karena dengan Pendidikan yang baik, maka orangtua dapat menerima segala informasi dari luar terutama tentang cara pengasuhan anak yang baik, bagaimana menjaga kesehatan anaknya, pendidikanya dan sebagainya. Pendidikan merupakan salah satu input dalam proses terbentuknya satuan keluaran perilaku yang berpengaruh terhadap kemampuan keluarga dalam melakukan tindakan sesuai yang diharapkan, sejalan dnegan hal tersebut Green dan Notoatmojo dalam (17) menyatakan bahwa pengetahun merupakan salah satu faktor predispoisi pada seseorang dalam pembentukan perilaku kesehatan.

Pengetahuan sangat erat dengan status pendidikan , dimana sesoerang berpendidikan tinggi maka orang tersebut memiliki pengetahuan yang luas. Pendidikan yang rendah tidak menjamin seorang ibu tidak mempunyai pengetahuan yang cukup mengenai gizi keluarganya. Hal ini sejalan dengan penelitian Liswati Pada tahun 2016 bahwa pendidikan, umur dan pekerjaan tidak ada hubungan yang signifikan dengan status gizi balita di wilayah Kabupaten Boyolali. Praktek pengasuhan yang kurang baik dan pendidikan ibu dapat mempengaruhi tingkat pengetahuan sesuai data demografi mayoritas ibu adalah berpendidikan SD, kurangnya pengetahuan ibu mengenai kesehatan gizi sebelum masa kehamilan, serta setelah ibu melahirkan juga dapat mempengaruhi tingkat kesehatan anak. Jika pengetahuan ibu sebelum melahirkan adalah tidak baik maka akan berdampak pada kesehatan gizi balita, Perilaku seseorang ibu tentang pemberian nutrisi pada anaknya sangatlah penting dalam tumbuh kembang anak. Mayoritas ibu tidak mengetahui bahwa status gizi anak tidak hanya fokus pada berat badan saja, tetapi tinggi badan juga termasuk dalam penilaian status gizi baita. namun masih didapatkan mayoritas keluarga berpengahasilan dibawah UMR dimana untuk memberikan kebutuhan gizi terhambat karena faktor ekonomi, hal ini akan berdampak pada status gizi anak yang terganggu. Pendidikan yang rendah tidak menjamin seorang ibu tidak mempunyai pengetahuan yang cukup mengenai gizi keluarganya.

Mayoritas ibu pada penelitian ini adalah ibu yang tidak bekerja. Hasil penelitian ini menunjukan tidak ada hubungan yang signifikan antara pekerjaan dengan status gizi balita stunting. Pekerjaan yang memadai akan menunjang tumbuh kembang anak, karena orangtua dapat menyediakan semua kebutuhan anak baik yang primer maupun yang sekunder. Keluarga dengan keadaan ekonomi yang baik akan menunjang status kesehatan dengan baik (18). Hal tersebut mengagambarkan bahwa keadaan social ekonomi keluarga mungkin akan mempengaruhi kemampuan keluarga dalam merawat anak. Pendidikan keluarga merupakan salah satu faktor yang penting dalam meningkatkan kemandian keluarga, karena dengan Pendidikan yang baik maka keluarga dapat memahami cara perawatan anak.dengan ibu yang tidak bekerja, banyak waktu yang diluangkan dirumah untuk merawa anaknyadan juga terpaparnya media informasi dari televisi dan radio dapat memeberikan informasi tentang kesehatan anak. Rasa ingin tahu yang tinggi dapat mempengaruhi ibu dalam mendapatkan informasi mengenai makanan yang tepat untuk anak. Pendidikan tidak harus diperoleh dari pendidikan formal saja tetapi bisa diperoleh memlaui pendidikan nonformal dimana dalam pengahasilan ekonomi untuk memenuhi kebutuhan sehari-hari mereka dibantu oleh beberapa keluarganya seperti kakek dan nenek yang pekerjaannya sebagai petani dan pedagang.

Mayoritas Jumlah anggota keluarga berjumlah 4 sampai 6 dalam satu keluarga.Hasil Penelitian ini menunjukan bahwa tidak ada hubungan yang signifikan antara jumlah keluarga dengan status gizi stunting. Jumlah anak yang banyak pada keluarga yang keadaan sosial ekonominya cukup, akan mengakibatkan berkurangnya perhatian dan kasih sayang pada anak, juga kebutuhan primer seperti makanan, sandang, dan perumahan pun tidak terpenuhi (16). Berdasarkan urain diatas peneliti berpendapat bahwa jumlah keluarga yang banyak dalam satu rumah akan berdampak pada pemberian nutrisi pada balita, kasih sayang yang kurang dan perhatian si ibu mengenai tumbuh kembang anak anaknya tidak merata, namun pada penelitian ini tidak ada hubungannya jumlah anggota keluarga, dengan status gizi stunting, karena mayoritas di daerah galis , terdapat banyak saudara sepupu yang hidup bersamaan dalam satu kampung, dimana saat anak saudaranya kesusahan dalam memberikan makanan, saudara tersebut saling berbagi, dan mengasihi sesama saudara.

\section{KESIMPULAN}

Mayoritas pendidikan di wiayah galis adalah ibu dengan pendidikan SD, Umur antara 18-35 
tahun,pekerjaan responden kebayakan ibu dengan tidak bekerja dan jumlah keluarga terbayak yaitu dengan 4-6 anggota keluarga dalam rumah. Tidak terdapat hubunga yang signifikan antara pendidikan pekerjaan umur dan jumlah keluarga responden dengan status gizi balita stunting. Faktor faktor yang mempengaruhi seperti keadaan balita, dan lingkungan tempat tinggal dapat mempengaruhi status gizi stunting, faktor faktor yang berhubungan dengan status gizi stunting dapat dilakukan oleh peneliti selanjutnya dengan tempat, waktu dan faktor faktor lainya yang berbeda agar mendapatkan hasil yang sesuai untuk menurunkan status gizi balita stunting. Faktor tersebutlah sangatlah multidimensional.

\section{UCAPAN TERIMA KASIH}

Kami mengucapkan terima kasih kepada Kepala Puskesmas Galis Bangkalan Madura, da bidan desa daan keer desa setempat untuk izin dan penerimaan kami untuk mengambil data sebagai bahan penelitian dan semua ibu yang telah bersedia menjadi responden.

\section{DAFTAR PUSTAKA}

1. Khoeroh H, Indriyanti D. Evaluasi Penatalaksanaan Gizi Balita Stunting Di Wilayah Kerja Puskesmas Sirampog. Unnes J Public Heal. 2017;6(3):189-95.

2. Vaozia S. Faktor Risiko Kejadian Stunting Pada Anak Usia 1-3 Tahun (Studi Di Desa Menduran Kecamatan Brati Kabupaten Grobogan). 2016.

3. Sisca D, Putri K, Nur D, Utami H, Teknologi P, Kesehatan I, et al. Nilai Batas Berat Lahir Sebagai Prediktor Kejadian Stunting Pada Anak Umur 623 Bulan Di Indonesia (Cut-Off Point Of Birthweight As Predictor Of Stunting In Children Aged 6-23 Months In Indonesia). 2015.

4. Harmoko. Asuhan Keperawatan Keluarga. Yogyakarta: Pustaka Pelajar; 2016.

5. Rahman MM, Saima U, Goni MA. Impact of maternal household decision-making autonomy on child nutritional status in Banglades. AsiaPacific J Public Heal. 2015;27(5):509-20.
6. Hermanussen M. Stunted growth. Eur J Clin Nutr. 2016;70(6):647-9.

7. WHO. Global Nutrition Target 2015: Stunting Policy Brief. World Heal Organ. 2012;14.3(9):18.

8. Kemenkes. buku panduan progam indonseia sehat. 2016.

9. Dewi M, Aminah M, Gizi J, Kesehatan P, Bandung K. Indonesian Journal of Human Nutrition Pengaruh Edukasi Gizi terhadap Feeding Practice Ibu Balita Stunting Usia 6-24 Bulan (The Effect of Nutritional Knowledge on Feeding Practice of Mothers Having Stunting Toddler Aged 6-24 Months). Indones J Hum Nutr. 2016;3(1):1-8.

10. Nadhiroh KN dan SR. Faktor Yang Berhubungan Dengan Kejadian Stunting Pada Balita. J Media Gizi Indones. 2015;10(Faktor yang berhubungan dengan kejadian stunting):13-9.

11. Ni'mah $\mathrm{K}$, Nadhiroh SR, Kesehatan DG, Kesehatan F. FAKTOR YANG BERHUBUNGAN DENGAN KEJADIAN STUNTING PADA BALITA.

12. Nadhiroh SR. Faktor yang berhubungan dengan kejadian. 2010;

13. UNICEF. Improving Child Nutrition - The achievable imperative for global progress. United Nations Children's fund. 2013.

14. Khasanah NA, Sulistyawati W. Karakteristik Ibu dengan Kejadian Gizi Kurang pada Balita 6-24 Bulan di Kecamatan Selat, Kapuas Tahun 2016. Str J Ilm Kesehat. 2018;7(1):1-8.

15. Lubis, N \& Pieter HZ. Pengantar Psikologi Dalam Keperawatan. Jakarta: Prenada Media; 2010.

16. Soetjiningsih. Perkembangan Anak dan Permasalahanya dalam Buku Ajar I Ilmu perkembangan Anak Dan Remaja. Jakarta: Sagungseto; 2012.

17. Patriyani. Marriage \& Familly Development. New York: Harper \& Row Publisher; 2009.

18. Muhlisin A. Keperawatan Keluarga. Yogyakarta: Goysen Publising; 2012. 